\title{
Artificial Intelligence Snake Robot (AISR)
}

\author{
Engr. Jose Marie B.Dipay ${ }^{\text {a }}$, Coleen Jerika P. Generoso ${ }^{b}$ \\ ${ }^{a}$ Faculty Researcher, Institute of Technology, Research Management Office, Polytechnic University of the Philippines \\ ${ }^{\text {b}}$ Polytechnic University of the Philippines
}

Article History: Received: 10 November 2020; Revised 12 January 2021 Accepted: 27 January 2021; Published online: 5 April 2021

\begin{abstract}
This study was conducted to design, develop and initially implement the Artificial Intelligence Snake Robot (AISR). Specifically, it identified the problems encountered in conducting manual rescuing people from natural calamity; the appropriate features of the tool that can be developed to address the problems encountered, and the respondents' level of acceptance of the user toward the developed tool in terms of performance, portability, operability, and efficacy. The research used the qualitative-quantitative research method that utilized a researcher-made questionnaire and interview questions. The respondents of the study were fifty (50) Life Rescuers, 25 (25) Red Cross Staff and 25 (25) Random People from different places. The problems encountered in manual rescuing people from natural calamity; hard time finding people lost during disaster, lack of new technologies and equipment, lack of K-9 dogs and burden of working on disaster area. The appropriate features of the tool that can be developed to address the problems encountered were: sensors can make the process of rescuing people faster and easier. The respondents' ratings for Artificial Intelligence Snake Robot (AISR) were extremely receivable in terms of performance (4.60); portability (4.54); operability (4.51); and efficacy (4.56). The government or other authorities will orient the proper use of the propose robot to avoid having a problem in rescuing people.
\end{abstract}

Keywords: Search and rescue, Robot Snakes, Motion panning, Smartphone based control

\section{Introduction}

Rescuers here in the Philippines are gaining some hard experiences in glancing through people who are gotten inside the systems that disintegrated after a seismic tremor has occurred. This endeavor is expected for rescue movement and will be filled in as the individual available to come in to work for peering inside the fallen structure after the tremor has occurred. The robot can take accounts and photos of people who are gotten and searching without a doubt fire clinical assistance. Tremor is one of the unpleasant and squashing essential marvels which cause incredible devilishness to the areas uncommonly the Philippines who have several parcel centers, conceded money related tumult and even killings scores of honest individuals. The most exceedingly terrible thing is that this endless unsafe power can happen abnormally, as it's an unexpected slip on the planet outside layer, making the earth shake and tremble passing on huge mischief to the general populace.

As seismic tremor questing is colossal these days, new advances are being grown any place all through the world. They can give better insurance and give intelligently unequivocal gauge of the seismic fiasco. This assessment is about an adaptable based control robot that may secure a titanic number of individuals if will utilize repercussions of the tremor. The motivation behind this assessment overhaul the salvage activity framework that will quickly save hurt individuals even the got ones.

\section{Objectives Of The Study}

The main problem that the design seeks an answer is the problems encountered in manual rescuing people from natural calamity, the appropriate features of the Artificial Intelligence Snake Robot that can be developed to address the problems encountered and the respondents' level of acceptance towards the developed robot in terms of performance, portability, operability and efficacy.

This study sought to answer the following questions:

1. What are the problems encountered in manual rescuing people from natural calamity?

2. What are the appropriate features of the Artificial Intelligence Snake Robot that can be developed to address the problems encountered?

3. What is the respondents' level of acceptance towards the developed robot in terms of?

\subsection{Performance;}




\subsection{Portability;}

3.3 Operability; and

\subsection{Efficacy?}

\section{Theoretical Framework}

It was proposed in 1936 by the biologist, Ludwig von Bertalanffy, and further enhanced by Ross Ashby, it is the Input-Process-Output (IPO) Model of evaluation based on the General Systems Theory that the researcher utilized.Precisely when we talk about IPO or Input-Process-Output, it is required dealing with assignments required to change responsibilities to yields and it is in like way a significant outline that sees the information sources, yields. The IPO Model offers a convincing system to both dismantle and record the hazardous bits of a change procedure on the off chance that it is utilized in a benefit or genuine way. The wellsprings of information pick the development of information and materials into the strategy considering. The yields are the information and materials spouting out of the change system. The models are now and then engineered to join any restrain that may occur in the process as well. The managing step intertwines all assignments required to influence a distinction in the information sources.The Input is formulating the concept of building the Artificial Intelligence Snake Robotsuch as USAR (Urban Search and Rescue) smart phone to be used as controller and the scene. For the implementation, it needs the integration of hardware and software.The process showed the data gathering including video footages, facial identities and location footages of where the person is found. Nextis gathering analysis that information to modify an existing Snake Robot then last is the deployment of final output.

The Output shown the outcomes of the disquisition and then the process featured the procedures underwent by the researcher in order to answer the sub-dilemmas and the last part is that the Input included the formulation of the system, the hardware, the software, and the implementation of the system.

\section{Materials And Methods}

The investigation utilized blended strategy for subjective and quantitative strategies for look into. Subjective research is a non-numerical, precise emotional methodology used to portray and to pick up knowledge by investigating the profundity, wealth, and multifaceted nature intrinsic in a phenomenon (Juni\&Afiah, 2014). The researcher conducted personal interview since the study focused on identifying problems encountered in rescuing people from natural calamity; and the appropriate features to be developed to address the problems encountered. He prepared a list of topics and questions to be used in the discussion with the proponent.

Quantitative research method, on the other hand, according to Zikmund (2003), shows how the numerically measurable variables are arranged, conceptually, in relation to each other. The researcher adopted an ISO 9126 (International Organization for Standardization) questionnaire to determine the level of acceptance by the respondents on the developed Artificial Intelligence Snake Robot The criteria of acceptance were limited to performance, portability, operability, and efficacy.

Likert Scale was used to describe the quantified responses of the respondents.

Table1

\begin{tabular}{|c|c|c|}
\hline Rating & $\begin{array}{c}\text { Numerical } \\
\text { Scale }\end{array}$ & $\begin{array}{c}\text { Level of } \\
\text { Acceptance } \\
\text { Verbal } \\
\text { Interpretation }\end{array}$ \\
\hline 5 & $4.60-6.00$ & $\begin{array}{c}\text { Extremely } \\
\text { Receivable }\end{array}$ \\
\hline 4 & $4.50-5.49$ & Receivable \\
\hline 3 & $2.50-3.49$ & $\begin{array}{c}\text { Moderately } \\
\text { Receivable }\end{array}$ \\
\hline 2 & $1.50-2.49$ & $\begin{array}{c}\text { Less Receivable } \\
\text { Not Receivable }\end{array}$ \\
\hline 1 & $1.00-1.49$ & . \\
\hline
\end{tabular}


The research was largely qualitative quantitative method in describing and interpreting the nature present and existing situation of the proposed system. In this way, this investigation was a descriptive research. Spellbinding exploration includes the assortment of information so as to test theory and to respond to questions concerning current status of the subject of the investigation (Sevilla, 1992).

The respondents of the study were fifty (50) Life Rescuers, 25 (25) Red Cross Staff and 25 (25) Random People from different places. All of them were selected through purposive sampling. Based on Crossman (2017) a purposive example is a non-likelihood test that is chosen dependent on qualities of a populace and the goal of study.

The respondents of the study were fifty (50) Life Rescuers, 25 (25) Red Cross Staff and 25 (25) Random People from different places. All of them were selected through purposive sampling. Based on Crossman (2017) a purposive sampa on

\section{Outcomes And Explanation}

1. The problems encountered in manual rescuing people from natural calamity

During the interview, the proponent shared four (4) issues in manual rescuing people from natural calamity namely: 1) hard time finding people lost during disaster; 2) lack of new technologies and equipment; 3) lack of K9 dogs; 4) burden of working on disaster area.

2. Respondents' Response for Appropriate Features to be Detailed to Acknowledged the Problems Encountered

The appropriate features of the robot that can be developed to address the problems encountered were: 1) sensors can make the process of rescuing people faster and easier; and 2) the whole unit was a successfully developed stand-alone robot that will allow rescuing people much faster and reliable.

3. Respondents' Level of Acceptance toward the Developed Machine

The respondents' ratings for Artificial Intelligence Snake Robot were extremelyreceivable in terms of performance, portability, operability and efficacy.

\section{Conclusions Andrecomendations}

\section{Conclusions}

A. The problems encountered in manual rescuing people from natural calamity that may cause hard time finding people lost during disaster, lack of new technologies and equipment, lack of K-9 dogs and burden of working on disaster area. $\mathrm{d}$ in manual rescuing people from natural calamity that may cause hard time finding people lost during disaster, lack of new technologies and equipment, lack of K-9 dogs and burden of working on disaster area.

B. The appropriate features of the robot that can be developed to address the problems encountered were: sensors can make the process of rescuing people faster and easier and the whole unit was a successfully developed stand-alone robot that will allow rescuing people much faster and reliable.

C. The respondents' ratings for Artificial Intelligence Snake Robot were extremelyreceivable in terms of performance, portability, operability and efficacy.

\section{Recommendation}

A. The government or other authorities will orient the proper use of the propose robot to avoid having a problem in rescuing people.

B. The government should also be having a seminar about how the technology helps in make our life easier, with this, they will get an idea to improve or to provide better machine that the proponent made.

\section{References}

Britsios, J. (2017). Webnauts.net. Retrieved from Why operability is important to you: http://www.webnauts.net/operability.html

Crossman, A. (2017, March 02). thoughtco. Retrieved from Understanding Purposive Sampling: An Overview of the Method and Its Applications: https://www.thoughtco.com/purposive-sampling-3026727

Rouse, M. (2017). searchmicroservices.techtarget. Retrieved from performance: http://searchmicroservices.techtarget.com/definition/performance 
"Mittika Ukey, Sonam Gupta, Bhagyashali Masane, Chanchal V.Dahat"(2016, March):Alive Human Detection Robot in RescueOperation

"Asha Gupta, Nidhee Panchal, Dhruti Desai, Divya Dangi, Mr. Viral Patel"(2014, November):Live Human Detection Robot"

Sevilla, C. G. (1992). Disquisition Methods: Revised Edition. Quezon City: Rex.

Thomas M. Cover, Joy A. Thomas (2006). Elements of Information Theory. John Wiley \& Sons, New York.

Weibull. (2013, March). Retrieved from Portability Importance: http://www.weibull.com/hotwire/issue145/tooltips145.htm

Zikmund, W. G. (2003). Business Disquisition Methods. Ohio: Thomson South-Western. 